\title{
Modelling and simulation of the traffic management in a migration phase: example of "Ligne 1" of the Parisian subway
}

\author{
M. Ghantous-Mouawad ${ }^{1,2}$, W. Schön ${ }^{1}$, J.-L. Boulanger ${ }^{1}$ \\ \& G. Churchill ${ }^{2}$ \\ ${ }^{1}$ Laboratoire Heudiasyc, Université de Technologie de Compiègne, \\ Centre de recherches de Royallieu, France \\ ${ }^{2}$ Régie Autonome des Transports Parisiens, RATP, France
}

\begin{abstract}
This paper gives a closer look to the subject of the conversion of a conventional metro line into a fully automated operation without interrupting or disturbing the service. In the introduction, we present the Line 1 Automation project as one of the principal aspects of Paris metro's network modernization plan announced by the Régie Autonome des Transports Parisiens (RATP). Next we give an overview of the present line 1 and illustrate the decision key elements for choosing it as a target of a fully automatic operation. The following section describes the development of the line 1 model and shows the results made so far. Finally, we expose the conclusions of the present work and the outlooks of the line 1 automation project.
\end{abstract}

Keywords: Paris subway network, fully automated operation, safety, simulation.

\section{Introduction}

Three phases have marked the RATP history. The period 1900-1935 was the birth of the Paris subway. The period 1955-1975 has known the first modernization wave with the technology breakthrough of the operational control centers (OCC), the automatic driving, the controlled manual train driving (CMC) and with the new generation of the rolling stock. The period 2005-2020 shall see the second modernization wave. A 50 years cycle gives rhythm to these evolutions. So the new phase engages the Paris subway for the next decades.

The functional and technical bases of the new modernization program have been defined by the RATP on April $26^{\text {th }}, 2002$. Being oriented towards the new 
technologies, the equipments modularity and their interchangeability, they (it) have permit to define the program known as OURAGAN (Offre Urbaine Renouvelée et Améliorée Gérée par un Automatisme Nouveau). The first implementation of OURAGAN shall take place on line 13 in 2007.

The modernization takes into account the accident report of Notre Dame de Lorette. On August $30^{\text {th }}, 2002$ at $13 \mathrm{~h} 21$, the leading car of a train of the line 12 lies down on the track in the distance between the stations Saint Georges - Notre Dame de Lorette, slips of a 50 meters distance and ends up by colliding with the platform edge coping, face to a train stopped in the opposite track. This accident, whose origin was due to a significant excess of speed, has led the RATP to program the network equipment of a continuous speed control in less than 15 years instead of 30 initially foreseen.

The report of the functioning of line 14, a fully automatic line (Line 14 put in service in October 1998), whose quality of service is approved by the majority of the French citizens and the operators around the world has been also integrated and the eventuality of automating an existing line is stated.

It is within the framework of this policy that the RATP has announced in January 2003 the launch of a feasibility study of line 1 automation Churchill [1].

The main challenge of that project is not automation itself, whose feasibility studies have been carried out and demonstrated by different well known projects made all over the world, including RATP previous experience with SAETMeteor, which is recognized as a technical and an economical success. Moreover, operation interruption of one of the most loaded Paris Metro lines being impossible, the main goal (which is a world's first) is to manage the migration phase, new automation equipments being installed during nights with the strong constraint to be able to resume normal operation a few hours later at the opening of the line. This task must be achieved without significant decrease of the quality of the service offered to the passengers and without any degradation of people safety, including operation staff. This latter concern is the cause of very specific problems during the transitory phase where cohabitation between manual and automated trains will be unavoidable.

In this context, RATP has developed a modeling and simulation software tool in order to be able to carefully analyze the different possible operation scenarios in the migration phase and therefore anticipating and assessing the subsequent risks. The aim of this work is to offer to decision makers a complete model of the line that allow to test different operation strategies during the phase where fully automatic trains and conventional manually driven trains will run together on the line, their performances and their capacity to adapt to technical, organizational and environmental disruptions. This model takes into account all the technical elements that are part of the control chain of trains movement's command, such as infrastructure, traction power supply, signaling, rolling stock, all in nominal and in all identified possible failure modes. The simulation is focused on the optimization of the operation, on the risk tolerance in cases of human or technical failure. Graphical user interfaces are developed for any potential user (engineers, trainers, and operators), the model being used as a validation but also as a training tool. 


\section{Line 1 overview}

Line 1 presents the following characteristics:

- $\quad$ Length : $16.6 \mathrm{~km}$

- Number of stations : 25 (23 underground stations)

- Number of trains : 52 (6 cars - $90 \mathrm{~m}$, rubber tyres rolling stock/ third rail power supply)

- Headway : $105 \mathrm{sec}$

- $\quad$ Trip time : $76 \mathrm{~min}$

- Capacity : 23.500 pas./hr/direction

- Commercial speed : $27.4 \mathrm{~km} / \mathrm{hr}$

One of the decision key elements for choosing line one to be equipped for fully automatic operation is the high request for adaptability and responsiveness of the transport offer.

An essential central axis of the common transport in the Ile de France region, Line 1 is extremely sensible to the demand variations because of its many connections and the areas that it crosses. The analysis of its traffic shows that in spite of a satisfactory average offer, line 1 does not respond to the travelers' requests and does not offer the expected service. We observe notably a particular overload during the rush hour, off-peaks hours, weekends and holidays

Its traffic is the most important in the subway network with an average of 725.000 trips per day and 207 million trips per year.

The screen doors, a complementary element of the automation avoid all the severe and serious travelers' accidents: falls on the tracks, suicides..., also frequent on line 1 and enhance the line regularity. Figure 1 represents the distribution of delays due to passengers based on 2003 data.

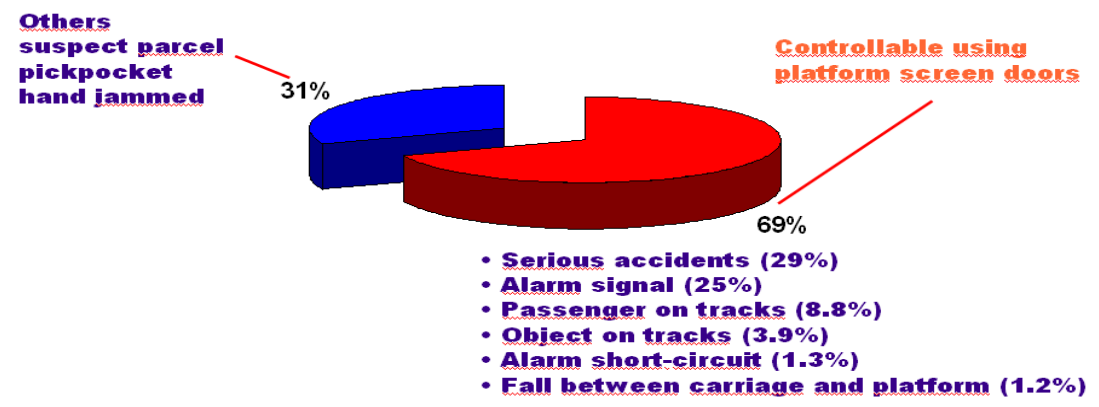

Figure 1: $\quad$ Distribution of delays due to passengers (last updated in 2003).

\section{Overview of the present safety management of the traffic}

The safety process is already identified for a conventional line such as Line 1 and for a driverless line such as Line 14. For each case of irregularity, accident, incident... specific regulations are to be followed and safety measured are to be 
made according to the regulations in order to minimize and if possible to avoid the negative consequences. Each time an agent notice an incident or an irregularity on a train, on a fix installation or in a station that disrupts or risks to disrupt the operating, he must inform and warn immediately the operator in charge at the OCC with all the useful details.

The operator in charge at the OCC, informed of an incident or an irregularity, take the necessary measures. In case of a driverless train, he is also kept informed by the specific alarms of incidents, irregularities occurred in the fields managed and supervised by the SAET.

The agents as soon as they are informed of the incident announce their presence to the chief operating manager who coordinates their intervention. He gives all the useful indications to the drivers and the station agents in order to inform the travelers.

\subsection{Definitions}

\subsubsection{Carrousel}

The carrousel manages the movement of the trains in the parking zone. It is defined by an entry position, an exit one and by the intermediate places between the two extreme positions. When a train penetrates the carrousel from the entry position, it is moved automatically from a parking place to the next one in the carrousel until it reaches the first unoccupied place. This recent technique, already applied on line 14, and compared to the traditional train movement management in the garage zone, has a benefit in saving time on operational basis inside a terminal.

\subsubsection{Priority table}

The priority table is a table that indicates on daily basis of service the different positions of the garage existing in the terminal. It gives for each position a certain priority used to determine the sequence of the parking mission. The priority table allows defining the type of the trains. In this table and for each simulation, we define the initial occupation state of the places in the garage, the number of equipped trains and non equipped trains present in the terminal and the rest of line 1 and their directions. A train is assigned a unique identity number. This number is determined in the priority table.

\subsubsection{SAET architecture}

The SAET architecture represented in figure 2 is a recapture of the OURAGAN architecture. The SAET is composed of the following technical modules:

- Modules of sector treatment which make it possible to safely manage the trains running. They are composed of sets of two calculators DIGISAFE in hot redundancy.

- Onboard treatment modules which make it possible to command the rolling stock. They are also composed of sets of two calculators DIGISAFE in hot redundancy. (Digisafe is a safety architecture for critical numeric applications, based on the coded monoprocessor principle. Following that principle a single processor manipulates coded 
variables and is therefore able to detect, on line and in real time, its possible errors (consecutive for example to hardware failures or perturbations from the environment) and in that case to act conveniently (going to a safe state by cutting off the power supply of the safe outputs, leading in general to stop the trains in the concerned zone.)

- Track negative detectors that detect a trespassing of a shunting signal in the stop position

- Input/Output modules allowing the SAET to interface with external systems.

- Data transmission system as a transmission vector between the different equipments of the SAET. It is composed of a double ring computer network and a radio transmission allowing the communications onboard/ground based on a product line used within the framework of the projects of New York, Barcelona and OURAGAN line 13

- The server of the maintenance help system

- The traction logic made out of relays of NS1 safety level (NS1 (Signalling Relay) is a design technique for safety relays, making it impossible to remain (consecutively to a failure) in the excited state (for example the return toward the desexcited state is ensured by gravity instead of a spring). The desexcited state is therefore designed to be the safe state (leading in general to stop the trains.)

- The OCC is composed of an operation room, a technical room and a training room that includes all the necessary hardware needed to simulate the traffic of the line and to replay real recorded situations.

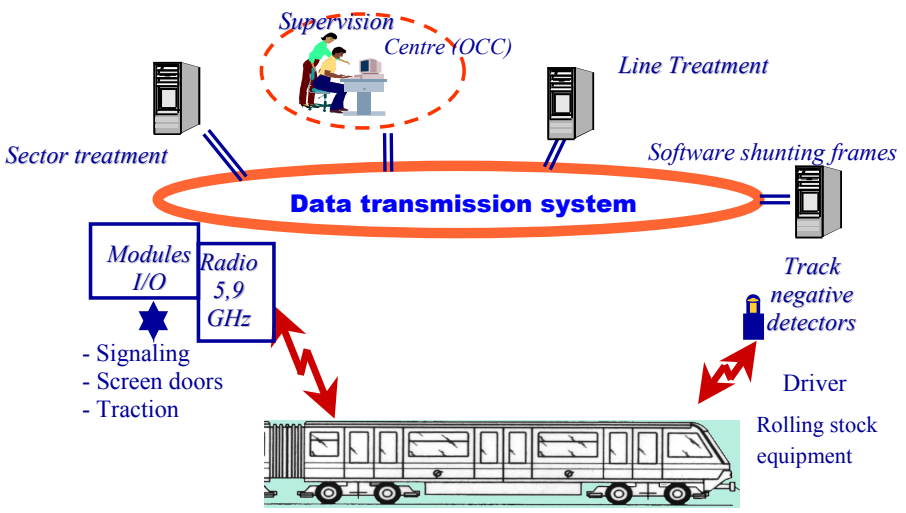

Figure 2: $\quad$ SAET architecture.

\subsubsection{Space-time principle}

A strong constraint of the traffic management is taken into account in the present Line 1 model: an equipped train is not allowed to run in a zone where agents are present on the tracks. Conversely, the access on secondary tracks is denied to drivers when an equipped train is detected in the related zone. In other words, an equipped train and a non equipped train cannot be present in the same place at 
the same time. On the other hand, they can occupy a same place but at different moments. This principle is known as space-time principle.

\subsubsection{Timetable}

The timetable is the daily plan of missions by which the train service is required to operate which can be selected prior to the start the operating day.

\subsection{Overview of the trains running management in case of a conventional line}

The line operating is normally checked and supervised by operators known as "chief operating managers" at the operational control centre (OCC).

The monitoring and the responsibility of the trains running as well as the definition and the implementation of the measures to make in case of incidents rest on:

- the chief operating manager and if necessary on the manager(s) of the terminals in case of a line managed by a modernized OCC

- in case of the other lines: on the chief operating manager for the line and on the chief departure manager for the terminals.

The coordination is managed by the chief operating manager.

In case of an incident and in the case of a line managed by a modernized OCC, the chief operating manager, if necessary the terminal manager(s) coordinates the terminals agents' tasks and decides of the measures to take in order to ensure an optimal service and to absorb the delays comparing to the normal basic schedule.

In the other cases, the chief departure managers coordinate the terminals agents' tasks. The chief departure manager, in constant communication with his homologue in the opposite terminal, decides of the measures to take in order to ensure an optimal service and to absorb the delays with regard to the original schedule.

In case of an incident, the chief operating or departure manager can, if necessary cancel one or many trains or modify a mission.

\subsection{Overview of the trains running management in case of a driverless line}

The line operating is normally controlled and checked by the SAET equipments and supervised by operators known as "OCC chief supervisors of operation" at the operational control centre (OCC).

The monitoring and the responsibility of the line operating, the trains running, the supervision of SAET equipment and the information to the travelers as well as the definition and the implementation of the measures to make in case of incidents rest on the OCC chief supervisors of operation.

The coordination is managed by the OCC chief supervisor of operation that fulfils the functions of the incident chief.

He decides also of the measures to take in order to ensure a booked stop and an optimal service and to absorb the delays comparing to the normal basic schedule. 
In case of incident (obstacle detection ...) interrupting the line examination, the OCC chief supervisor of operation asks for a driver intervention on the train board.

The OCC chief supervisor of operation, according to the information given by the driver:

- Either authorizes the automatic train operation for the rest of the trip while the driver stays onboard till the end of the trip.

- $\quad$ Or orders the manual train driving for the rest of the trip.

When the deterioration is perceptible, the OCC chief supervisor of operation asks the intervention of a qualified agent from the concerned technical service to check the concerned area.

The line examination being done and the potential incidents being solved, the line operating is then authorized.

The regular trains are put in service, automatically by the SAET, in accordance with the daily operating program.

A train needs a mission in order to move. The mission defines the trip and the tasks to be done by a train.

The management of these missions is ensured by the SAET from the OCC. These missions are normally chained.

\section{Results}

The specific safety regulations are not yet defined for the transitory phase. Therefore RATP is developing a software tool that allows the simulation of the traffic of line 1 in the present, the transitory and the target phase, in order to determine the safety measures for this phase without disturbing the service.

The results made so far are the development of the train based on the specifications of [4] and of the traffic of the two terminals of Line 1: Grande Arche de la Défense and Château de Vincennes based on the specifications given by $[2,3,5]$.

\subsection{Train development}

\subsubsection{Brief description}

The main functions of a train are the traction, the braking and the service to passengers. It is composed of six cars, four of them are central driving cars $(\mathrm{N})$ and the other two are trailers (S). In case of an ET, a trailer has a control panel. In the other case, it has a control cab. The train model developed is composed of the dynamic model of the MP89 coupled with the feedback control loop. This loop helps the train to calculate his position, velocity and acceleration while taking into account the values of these outputs at the previous moment. We calculate the train position by simple integration of the velocity while taking into consideration the traffic direction. The dynamic model of the MP89 is based on the resolution of the differential equation of the train movement for given characteristics of the line and the rolling stock, by analyzing the forces that appear at the rail-wheel contact. Consequently, the speed and the acceleration of 
the train are known. By simple integration the speed and by taking into account the traffic direction, we determine the train position. The train feedback performances are identical for the future driverless train of line 1 (MP05) and the present conventional train (MP89), except the driver reaction times in case of a MP89. It is taken into account when the driver changes his control cab in order to change the train direction ( 30 seconds approximately) and it is higher than the reaction time of a MP05 ( 2 to 3 seconds). An initialization phase is launched at the beginning of each simulation. It provides to the train the needed input parameters as well as the line 1 characteristics such as the declivity of the two main tracks and the speed limits implemented throughout the line in the two directions. These speed limits are not identical for the MP05 and the MP89. The train load (from 0 to 10 passengers $/ \mathrm{m}^{2}$ ) is indicated also before each simulation. It characterizes the travellers flow in the terminal for a given schedule. The user will define the maximum capacity of the travellers in a menu. In the present train model, the defined capacity is 722 travellers.

\subsection{Development of the traffic}

Figure 3 gives an overall architecture of the terminal model and his environment. It is a structured architecture composed of six main blocks.

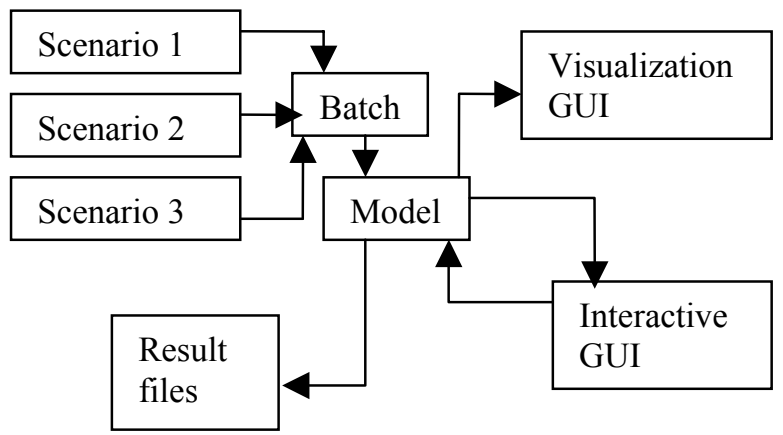

Figure 3: Terminal model structure.

Model is the central unit. Coded in Matlab/Simulink, it is responsible of all the basic operations. At the end of each simulation, two result files are generated. The first contains all the events already appeared in the GUI. The second gives more detailed information about the missions, the routes management and presents a summary of the delays of each train. The simulation reports in real time the position of the selected train, its type; its kilometer point, its velocity, its mission and the value of the delay. The visualization GUI displays also the significant events that happen during the simulation such as delays, train blocking situations, perturbations created, simulation hour and zone violation. This last point is based on the space-time principle defined above. The interactive graphical user interface offers the possibility to inject perturbations in 
real time and to combine them in order to create a complex degraded situation. We can create a perturbation by affecting a delay to a selected train or by forcing a train to stay at the station. We can also reverse the type of a train either through the MMI at every moment or through the timetable. We can also order a train parked in the garage to come out from its parking or its reserve position. We can also stop or move a train and restrict a track zone to be accessed by a MP05 or a MP89. We can modify the trip plan of a train by changing its missions, by inserting perturbations or by entering new missions. Equipments can be forced to stay in a predefined state (occupied track circuit, blocked crossings and switches, non functioning light...). When the train achieves his current mission, it goes into a no mission state where he waits for a new mission. When a new mission is assigned to a train by the operator from the MMI, it is taken into account only when his current mission is over. The pre planned following mission is cancelled automatically when the new mission is taken into account. Scenario is an Excel file composed of two major parts: the priority table and the timetable. The second part of the Scenario file is the timetable. In this timetable, the user assigns a schedule plan to the trains present in the terminal and the rest of line 1 . The schedule plan is the sequence of the missions given to a train that it shall follow during its trip to the opposite terminal. In the terminal Château de Vincennes, we find a train washing machine that we can activate through the timetable. Batch is an excel file that offers the possibility to launch a series of simulation, to record the results, to reduce the parking time at the station and to activate the carrousel.

\section{RATP - Simulation du terminus Chateau de Vincennes}

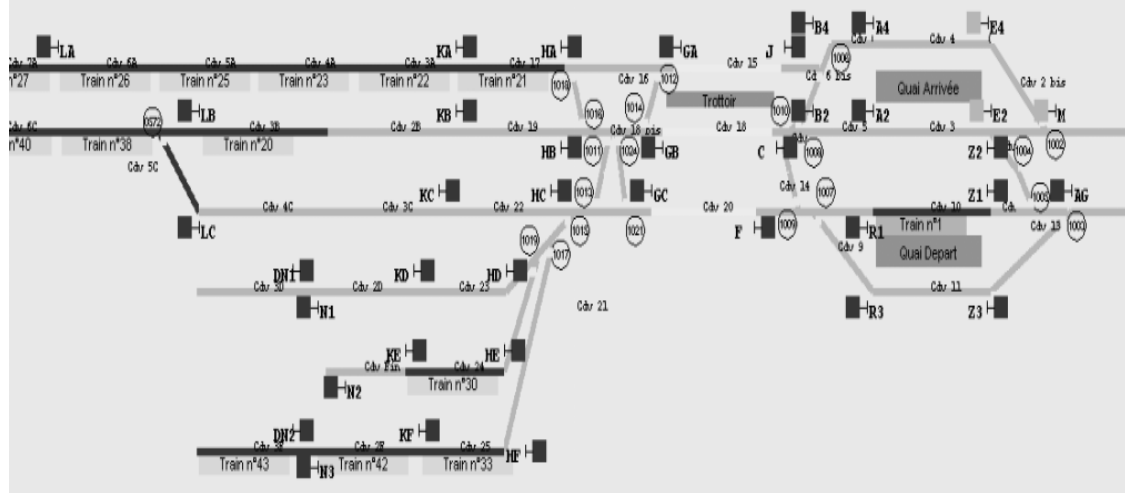

Figure 4: Visualization of the terminal Château de Vincennes animated by the trains running.

\section{Conclusions}

The actual Line 1 model allows separately the simulation of the traffic of its two terminals: Grande Arche de la Défense and Château de Vincennes, by 
considering the rest of the line as a black box. Figure 4 is a visualization of Château de Vincennes animated by the trains running.

This model is currently being completed by inserting the rest of the stations. It will also take into consideration all the future improvements and modifications made on line 1 infrastructure and on the rolling stock.

\section{Outlooks}

In 2011, line 1 shall be entirely automated

- July 2007: start of the reinforcement work of the platform edge coping

- January 2008: start of the installation of the screen doors

- May 2008: delivery of the first MP05 to the centre of railway tests in Valenciennes

- July 2008: delivery of the first train for commissioning

- January 2009: Commissioning of the OCC version manual train driving

- July 2009: Commissioning of the OCC version train manually driven/driverless train

- August 2009: Commissioning of the first driverless train and start of the cohabitation period between driverless trains and trains manually driven running on the same line.

With a delivery rate around 2 to 3 trains per month, line 1 shall be entirely and completely an automated operation in February 2011. The RATP then shall be among the firsts in the world who has carried out and has accomplished the conversion of a conventional subway line into an automated operation without traffic interruption.

\section{References}

[1] Churchill, "L'opération d'automatisation de la ligne 1 du métro de Paris", RATP, Paris, France, December 2005.

[2] Département Métro, US FDC, Réglementation Ferroviaire et Mouvement des trains, CONSIGNE DE SECURITE FERROVIAIRE 01-001, "METRO LIGNE 1, GARE DE CHATEAU DE VINCENNES", RATP, Paris, France, March 1995.

[3] Département MTS, US FDC, Réglementation, CONSIGNE DE SECURITE FERROVIAIRE 01-002, "MTS LIGNE 1, GARES DE PORTE MAILLOT, ESPLANADE DE LA DEFENSE, LA DEFENSE", RATP, Paris, France, January 2001.

[4] ET 4-10460 G, "Spécification fonctionnelle MP89", RATP, Paris, France.

[5] IEF-SR 04-5169, "Caractéristiques actuelles d'exploitation de la ligne 1", RATP, Paris, France, November 2004. 